\title{
Are Process Indicators Adequate to Assess Essen- tial Obstetric Care at District Level? - A Case Study from Rufiji District, Tanzania
}

\author{
David P Urassa',2, Anders Carlstedt², Lennarth Nyström³, Siriel N Massawe' ${ }^{1}$, Gunilla Lindmarke
}

\begin{abstract}
To assess coverage and quality of essential obstetric care (EOC) and the appropriateness of using process indicators, a 3month follow-up study was done in Rufiji district, Tanzania, involving 2 hospitals, 4 health centres, 10 large dispensaries and 10 randomly selected small dispensaries. Data collection was done on process indicators as suggested by UNICEF/ WHO/UNFPA (UN) and 'unmet obstetric need (UON) for major obstetric intervention (MOI)'. With standard values in (brackets), the district had two comprehensive EOC facilities, births in EOC amounted to 62\% (15\%), met need for EOC was 76\% (100\%), caesarean section (C/S) rate 4.1\% (>5\%), hospital case fatality rate (CFR) $1.0 \%(<1 \%)$ and successful obstetric referrals $46 \%$ (100\%). MOI for absolute maternal indication in the district was 2.6\% (1-2\%). All four maternal deaths occurred due to transport failures. The process indicators gave contradictory impressions on the coverage and quality of care and failed to link to the outcome of delivery complications in the study. (Afr J Reprod Health 2005; 9[3]:100-111 )
\end{abstract}

\section{RÉSUMÉ}

Les indicateurs du processus sont-ils adéquats pour évaluer le soin obstétrique essential au niveau du district? Une étude de cas du district de Rufiji, Tanzaniae Afin d'évaluer l'étendue et la qualité du soin obstétrique essentiel (SOE) et le caractère approprié de l'emploi des indicateurs de processus, une étude d'une durée de trois mois qui est basée sur des suivis médicaux, a été menée dans le district de Rufiji, Tanzanie, auprès de deux hôpitaux, quatre centres médicaux, diz grandes pharmacies et dix petites pharmacies selectionnées au hasard. Les données ont été recueillies à l'aide des indicateurs du processus comme l'ont préconisé l'UNICEF/OMS/UNFPA(ONU) et "le besoin obstétrique nonsatisfait $(\mathrm{BON})$ à propos des interventions obstétriques principales (IOP)". Avec les valeurs normales (entre guillemets) le district disposait de deux structures de SOE, le taux de naissance par rapport au SOE s'est élevé à 62\%(15\%), le taux du besoin non-satisfait par rapport au SOE était de 76\%(100\%), le taux d'opération césarienne (OC) était de 4,1\%( $<5 \%$ ), le taux du dècès des patients à l'hôpital (TDH) 1,0\% (<1\%) et les orientations vers les services spécialisés étaient de $46 \%$ $(100 \%)$. L'IOP par rapport à l'indication maternelle absolue dans le district était de 2,6\% (1-2\%). Tous les quartre dècès maternels se sont produits à cause du manque de transport. Les indicateurs du processus ont signalé des impressions contradictoires en ce qui concerne la coverture et la qualité de soin et ils n'ont pas pu se lier au résultat des complications liées à l'accouchement dans l'étude. (Rev Afr Santé Reprod 2005; 9[3]:100-111)

KEY WorDs: Quality of obstetric care, met needs, process indicators, program evaluation, Africa.

${ }^{1}$ Departments of Community Health/Obstetrics and Gynaecology, Mubimbili University College of Health Sciences, Dar es Salaam, Tanzania. ${ }^{2}$ Department of Women's and Children's Health, International Maternal and Child Health, Uppsala University, Uppsala, Sweden. ${ }^{3}$ Department of Public Health and Clinical Medicine, Epidemiology, Umea University, Umeå, Sweden

Correspondence: David P. Urassa, E-mail: durassa@muchs.ac.tz 


\section{Introduction}

Monitoring of progress towards the reduction of maternal mortality will require reliable and internationally comparable data. Process indicators can provide useful information especially in countries with weak vital statistics ${ }^{1}$. The conventional maternal and child health services have been criticised for emphasis more on the child than on maternal care ${ }^{2}$.

Maternal mortality ratio (MMR) in Tanzania is reported to be between 529 and 1500 per 100,000 live births ${ }^{3-5}$. The main causes of maternal mortality are haemorrhage, abortion, hypertension, anaemia and sepsis ${ }^{4,6}$. Most maternal deaths occur as unpredictable obstetric emergencies, thus a strategy to achieve a substantial decline of maternal mortality must prioritise improvement in medical treatment of obstetric emergencies ${ }^{4}$. Reduction of maternal and perinatal mortality depends to a great extent on improved accessibility to quality obstetric services such as surgery and blood transfusion that can only be provided in hospital settings ${ }^{7,8}$, but also on technically simple medical interventions for sepsis and bleeding.

Maternal health has been monitored using outcome indicators such as the maternal mortality ratio (MMR). Where no comprehensive vital statistics exists, it is difficult and costly to get data for these indicators. Process indicators have been advocated since they are considered easier to measure and can give information on events that affect maternal mortality as well as activities needed to prevent it ${ }^{1}$.

An alternative approach is a system of process indicators expressed as Unmet Obstetric Need $(\mathrm{UON})^{9}$. Several of these indicators are developed to compare the actual situation with estimated rates of complications and necessary interventions in the population.

The main objective of this study was to assess the coverage and quality of essential obstetric care (EOC) in rural Tanzania and to discuss the appropriateness of these process indicators.

\section{Subjects and methods}

\section{Study setting}

Rufiji district is one of the six districts of the Coastal region in Tanzania. In 1999 the district had an estimated population of 180,000, based on the 1988 Census and an annual population growth of $2.3 \%$. Geographically the Rufiji River intersects the district from West to East, dividing it into flood plain, coastal-delta, and plateau (hill) zones. The roads in the district are not passable during the rainy season and the limited transport system makes people dependent on the available health services within the district. The district has 54 health institutions including private facilities that provide delivery services, out of which 48 are dispensaries, 4 rural health centres (RHC) and 2 hospitals. One of the hospitals is a government district hospital and the other is a voluntary hospital run by a religious organisation. Based on a birth rate of 4\%, 7,200 births annually were estimated ${ }^{10}$.

\section{Study design and study period}

This was a descriptive study of all institutional deliveries in Rufiji district during a 3-month period, from 15th November 1999 to 14th February 2000 i.e. during the dry season. 


\section{Study participants and sampling}

All institutions were stratified by type of unit providing deliveries and number of deliveries, thus stratum I consists of all hospitals $(n=2)$, stratum II of all RHCs ( $n=4)$, stratum III of all large dispensaries with more than five monthly deliveries $(n=10)$, and stratum IV of 10 randomly selected out of 38 small dispensaries. The 26 units selected constitute $48 \%$ of all health institutions in the district. This fulfils the recommendations to cover at least $25-30 \%$ of the health institutions when assessing quality of care ${ }^{1,11}$. All women who attended the selected health facilities for delivery in the three-month duration were included in the study.

\section{Data collection}

Data collectors were the health workers at each selected health institution. An introductory meeting was held on the first day in each institution to familiarise the staff, explain the aim of the study and train them on data collection. It was emphasised that the research team was not representing the Ministry of Health and that the findings of this study would not be used against any of them.

Standard diagnostic definitions for different complications were introduced in the training to be used uniformly by all the research assistants. Health workers were encouraged to record all the events occurring to patients reported with complications. The diagnoses were reviewed by a specialist obstetrician. If a woman had more than one complication the most immediately lifethreatening was selected.

We established a parallel data collection on information about complications since the routine data collection system reported delivery complications only as abnormal without specifying the type of abnormality. Information for quality assessment (i.e. structural, process and outcome variables) was collected. For structural quality, a standard checklist was developed and information on availability of the following items was collected monthly: number of qualified staff, functioning vacuum extractor, dilatation and curettage set, injectable antibiotics, oxytocics and anti-convulsant drugs, blood bottles, functioning operation theatre and blood transfusion facilities.

Using UN process indicators ${ }^{1} \mathrm{a}$ form was filled for each woman with a delivery complication. Monthly visits by the investigator were made to all health institutions to collect data and to cross check and correct any discrepancy between the additional form and the routine data collection records of the institution. The forms of all women with complications were checked at all referral levels to avoid duplicates.

Definitions and standards

As trained staff were regarded as those who had at least two years of midwifery in their basic training, thus in this study a $\mathrm{MCH}$ aide (with two years of midwifery training) was the lowest cadre of trained staff. They are specifically trained for immunisation and growth monitoring of under fives and antenatal care at $\mathrm{MCH}$ clinics, as well as to conduct low risk deliveries and to immediately refer women with complications.

\section{Met obstetric need}

The UN indicators define as obstetric complications antepartum (APH) and postpartum (PPH) haemorrhage, prolonged/obstructed labour, postpartum sepsis, complications due to abortions, pre-eclampsia/eclampsia, ectopic pregnancy and ruptured uterus. Basic EOC functions include providing injectable antibiotics, injectable oxytocics, injectable anti-convulsants, manual removal of placenta, removal of retained products, and assisted vaginal delivery. Comprehensive EOC functions include all six basic functions and also $\mathrm{C} / \mathrm{S}$ and blood transfusion. 
Minimal acceptable levels of EOC are:

- $\quad \geq 4$ basic and 1 comprehensive EOC institutions per 500,000 inhabitants

- $\quad \geq 15 \%$ of all births in the population take place in either a basic or a comprehensive EOC institution

- All women expected to have obstetric complications should be treated in EOC institutions (Met need for EOC)

- $\mathrm{C} / \mathrm{S}$ : between $5 \%-15 \%$ of all births in the population

- $\quad$ CFR $<1 \%$ of women with obstetric complications in EOC institutions.

In the preliminary analysis we found that most institutions had not handled all types of complications in the study period and therefore had not performed all types of recommended interventions. We therefore combined structural and process indicators of quality to modify the UN definition of basic and comprehensive EOC based on the assumption that in the presence of standard drugs and the skills required to inject/deliver those drugs (antibiotics, oxytocics and anti-convulsants) the facility qualified for EOC. Thus, a basic EOC institution was defined as one that had the required injectables in stock and had performed parenteral administration of any one of the drugs, and in addition had performed either one of the following minor surgical procedures: removal of placenta, evacuation of retained products, or assisted vaginal delivery, i.e. vacuum extraction/forceps delivery. A comprehensive EOC institution was defined as an institution that, in addition to basic EOC requirements, had provided blood transfusions and surgery within the period of study.

\section{Unmet obstetric need (UON)}

The UON indicators define major obstetric interventions (MOI) in relation to absolute maternal indications (AMI), which can only be performed in hospitals to include: C/S, laparotomy, hysterectomy, internal version and craniotomy. Absolute maternal indications are severe APH, severe PPH, major Cephalo-pelvic disproportions (CPD), transverse position and brow presentation. The concept of reference ratio (RR) of $1-2 \%$ deaths of all deliveries has been used to mean the maximum expected maternal mortality ratio (MMR)in areas with no maternal care ${ }^{9}$ and therefore need a corresponding MOI for AMI to avert maternal deaths. The complications and interventions presented at hospital level were therefore re-categorized to fit into the UON classification. Only women residing in the study area were included and no MOI for AMI was performed on the study population outside of the district. Applying the RR on the number of expected births (EB) per catchment population, gives the expected number of women who should have had a MOI for the above-mentioned AMI. Unmet obstetric need was calculated using the formula:

$$
\mathrm{UON}=(\mathrm{EB} \times \mathrm{RR})-(\mathrm{MOI} \text { for } \mathrm{AMI}) .
$$

Ideally, the RR should be established locally. Since we did not have MOI for AMI, RR for Tanzania we used a benchmark of $1-2 \%$ as suggested in studies from Morocco ${ }^{12}$ and Mali $(1.2 \%)^{13}$. NB: The Moroccan study was the first of its kind to utilize the UON concept and the established reference ratio from this study was recommended to be used in other areas of similar characteristic where local reference ratio was not yet established.

\section{Results}

\section{Coverage}

The study population covered by the catchment population of the selected 26 health facilities was 155,000 , and that is $86 \%$ of the 180,000 estimated district population. Figure 1 highlights a diagrammatic presentation of delivery or pregnancy complication information in the study area during a 3-month period of data collection. 
104 African Journal of Reproductive Health

In that period, there were 1,427 women of whom 176 had normal home deliveries and 1,046 uncomplicated institutional deliveries. Two hundred and five women were managed by the health-care system due to delivery or pregnancy complication. The complications included 58

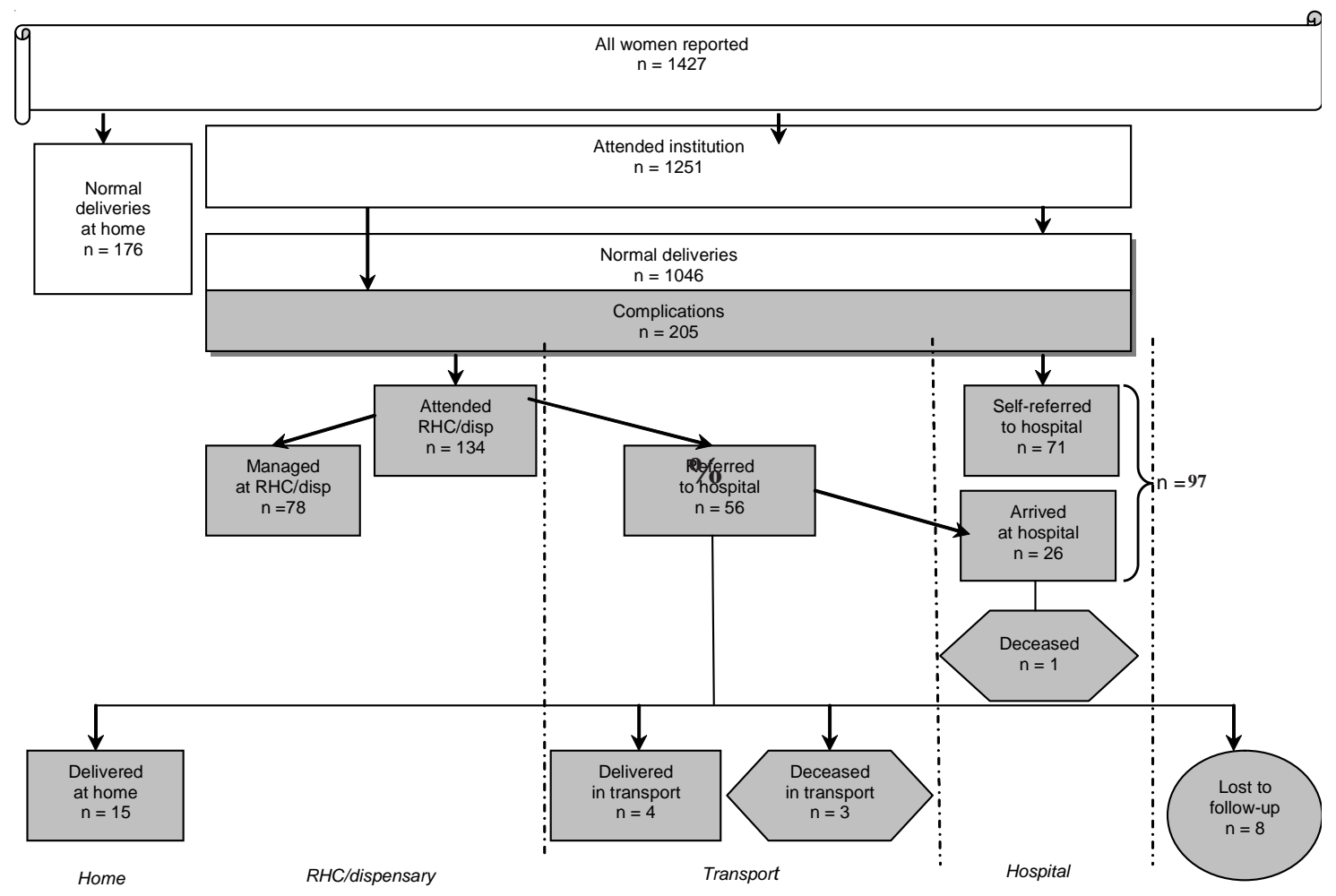

Figure 1. Flow chart on normal and complicated deliveries and pregnancy complications in Rufiji district

Table 1. Number of non-, basic-, and comprehensive EOC institutions among dispensaries, rural health centres and hospitals

\begin{tabular}{llllll}
\hline EOC status & \multicolumn{3}{l}{ Health institutions } & Total \\
\cline { 2 - 6 } & \multicolumn{2}{l}{ Dispensaries } & Health centres & Hospitals & \\
& Small & Large & & 0 & 13 \\
\hline Non & 8 & 5 & 0 & 0 & 11 \\
Basic & 2 & 5 & 4 & 2 & 2 \\
Comprehensive & 0 & 0 & 0 & 2 & 26 \\
\hline Total & 10 & 10 & 4 &
\end{tabular}


abortions and two ectopic pregnancies (total 60) and therefore total number of deliveries was 1,367 (1,427 minus 60). Adjusting for the coverage of $86 \%$ of the population, the total number of deliveries in the district was estimated at 1,587.

Whereas two dispensaries had a shortage of the three essential EOC drugs, all RHC and hospitals had these drugs. Unlike all health centres and hospitals, where all the required interventions were performed, more than half of the dispensaries performed neither parenteral administration of one of the drugs nor any minor surgical intervention within the 3-month study period. Both hospitals qualified for comprehensive EOC, whereas all RHCs but only five out of 10 large and two out of 10 small dispensaries qualified for basic EOC (Table 1).

\section{Met obstetric need using UN indicators}

In the three-month period, $72 \%$ ((691 plus 291)/ $1,367)$ of all observed births or $62 \%(982 / 1,587)$ of the expected number of births took place in EOC institutions being far in excess of the 15\% reference given for the UN indicators (Table 2). Out of women with recorded complications $86 \%(177 / 205)$ were managed at EOC institutions, which is $74 \%(177 / 238)$ of the expected number for the whole district (met need).

Table 2. Number and percentages of women with normal deliveries and complications by EOC status

\begin{tabular}{|c|c|c|c|c|c|c|c|c|}
\hline \multirow[t]{3}{*}{ Deliveries } & \multicolumn{6}{|c|}{ EOC status } & \multirow{2}{*}{\multicolumn{2}{|c|}{ Total }} \\
\hline & \multicolumn{2}{|c|}{ Non } & \multicolumn{2}{|c|}{ Basic } & \multicolumn{2}{|c|}{ Comprehensive } & & \\
\hline & No. & $\%$ & No. & $\%$ & No. & $\%$ & No. & $\%$ \\
\hline Normal & 241 & 23 & 611 & 58 & 194 & 19 & 1046 & 100 \\
\hline Complications & 28 & 14 & 80 & 39 & 97 & 47 & 205 & 100 \\
\hline Total & 269 & 22 & 691 & 55 & 291 & 23 & 1251 & 100 \\
\hline
\end{tabular}

Table 3. Number of complications seen in health institutions, EOC actions, and referrals and compliance with referrals

\begin{tabular}{|c|c|c|c|c|c|c|c|c|}
\hline \multirow[t]{2}{*}{ Type of complication } & \multicolumn{3}{|c|}{ Health institution } & \multicolumn{2}{|c|}{$\begin{array}{l}\text { No. of EOC } \\
\text { actions } \\
\end{array}$} & \multicolumn{2}{|l|}{ No. of } & \multirow[t]{2}{*}{ Total } \\
\hline & DIS & $\begin{array}{l}\text { RHC } \\
\text { C }\end{array}$ & HOS & $\geq 1$ & 0 & $\begin{array}{l}\text { Referrals } \\
\mathrm{s}\end{array}$ & $\begin{array}{l}\text { Comp- } \\
\text { liances }\end{array}$ & \\
\hline Haemorrhage (APH + PPH) & 20 & 8 & 12 & 37 & 3 & 12 & 2 & 40 \\
\hline Prolonged/obstructed labour & 17 & 14 & 45 & 73 & 3 & 26 & 18 & 76 \\
\hline Sepsis & 7 & & 1 & 8 & & 2 & 0 & 8 \\
\hline Abortion & 15 & 33 & 10 & 58 & & 2 & 1 & 58 \\
\hline Pre-eclampsia/eclampsia & 5 & 1 & 2 & 6 & 2 & 6 & 2 & 8 \\
\hline Ectopic pregnancy & 1 & 0 & 1 & 2 & & 1 & 1 & 2 \\
\hline Ruptured uterus & 1 & & & 1 & & 1 & 1 & 1 \\
\hline Other (incl. foetal indications) & 4 & 8 & & 7 & 5 & 6 & 1 & 12 \\
\hline Total & 70 & 64 & 71 & 192 & 13 & 56 & 26 & 205 \\
\hline
\end{tabular}

African Journal of Reproductive Health Vol. 9 No.3 December 2005 
106 African Journal of Reproductive Health

Among the complications 71 were self-referred to hospital and 134 attended a RHC or a dispensary, of which 78 were managed there and 56 were referred to hospital (Figure 1). The most common complication managed at dispensaries was postpartum haemorrhage, whereas abortions were most prevalent at the health centres. Prolonged/obstructed labour was the most common obstetric complication among women who were primarily seen at hospital level, and this complication was also the predominant cause of referral (Table 3).

Our analysis of the case management of complications indicates that treatment was adequate even in small dispensaries that did not qualify as basic EOC units. No maternal death can be attributed to mismanagement at dispensary or health centre level. The four women with complications who died during transport or shortly after arrival in hospital (see below) were all referred as emergencies from basic EOC facilities. The referral diagnoses were postpartum sepsis (1), imminent rupture of the uterus in "grand multipara"(1) and Cephalo pelvic disproportion (2).

Fifty-six patients were referred to hospital; however 30 did not arrive at either of the two hospitals. Twenty-two of these women were traced and interviewed for their outcome in the community. Three died on the way to the hospital, whereas 19 had delivered at home or on the way to hospital. The only hospital death occurred in a woman arriving at the government hospital with a ruptured uterus, after waiting more than three days for transport. Thus, all maternal deaths in this study can be attributed to lack of transport and/or inability to pay for hospital care. This was confirmed by interviews with women who did not adhere to the referral advice (see below).

Considering the 3 women who died during transport and 4 who delivered on the way to the referral point, the referral compliance rate was $59 \%$ (that is 26 who arrived at hospital plus 7 who either delivered or died on the

Table 4. Major obstetric interventions (MOI) for absolute maternal indication (AMI) and non-AMI in relation to distance travelled by women to the hospitals in Rufiji district

\begin{tabular}{|c|c|c|c|c|c|c|}
\hline & \multicolumn{4}{|c|}{ Distance travelled } & \multicolumn{2}{|c|}{ Total } \\
\hline & \multicolumn{2}{|c|}{$\leq 10 \mathrm{~km}$} & \multicolumn{2}{|c|}{$>10 \mathrm{~km}$} & \multirow[b]{2}{*}{ No. } & \multirow[b]{2}{*}{$\%$} \\
\hline & $\mathrm{C} / \mathrm{S}$ & Laparatomy & $\mathrm{C} / \mathrm{S}$ & Laparatomy & & \\
\hline \multicolumn{7}{|l|}{ Absolute maternal indications: } \\
\hline Severe antepartum haemorrhage & & & 2 & & 2 & 4.3 \\
\hline Cephalo-pelvic-disproportion & 5 & & 31 & & 36 & 78.4 \\
\hline Malpresentation & 1 & & 4 & & 5 & 10.9 \\
\hline Ruptured uterus & & & & 1 & 1 & 2.1 \\
\hline Ectopic pregnancy & & & & 2 & 2 & 4.3 \\
\hline Sub-total: AMI & 6 & 0 & 37 & 3 & 46 & 100 \\
\hline \multicolumn{7}{|l|}{ Non-absolute maternal indications: } \\
\hline Dynamic dystocia/previous C/S & & & 6 & & 6 & 27.3 \\
\hline Foetal distress & 1 & & 3 & & 4 & 18.2 \\
\hline Cord prolapse & & & 2 & & 2 & 9.1 \\
\hline Breech & 1 & & 2 & & 3 & 13.6 \\
\hline Eclampsia & & & 4 & & 4 & 18.2 \\
\hline Others & 1 & 2 & & & 3 & 13.6 \\
\hline Sub-total: Non-AMI & 3 & 0 & 19 & 0 & 22 & 100 \\
\hline Total & 9 & 0 & 56 & 3 & 68 & \\
\hline
\end{tabular}


Table 5. Unmet need of major obstetric interventions (MOI) for absolute maternal indications (AMI) in Rufiji by distance from hospital

\begin{tabular}{|c|c|c|c|c|c|c|c|}
\hline \multirow[t]{2}{*}{$\overline{\text { Area }}$} & \multirow{2}{*}{$\begin{array}{l}\text { Distance } \\
\text { from } \\
\text { hospital; } \\
(\mathrm{km})\end{array}$} & \multirow[t]{2}{*}{ Population } & No. of EB per & $\begin{array}{l}\text { No. of MOI for AMI } \\
\text { per } 3 \text { months }\end{array}$ & \multicolumn{2}{|c|}{$\begin{array}{l}\text { Perfomed } \\
\text { minus } \\
\text { expected }\end{array}$} & \multirow[t]{2}{*}{$\begin{array}{l}\text { Met Need } \\
\text { Rate/100 EB }\end{array}$} \\
\hline & & & $\begin{array}{l}\text { Year } 3 \text { months } \\
(4 \%)\end{array}$ & $\begin{array}{l}\overline{\text { Expected Performed }} \\
(1 \%)\end{array}$ & No. & & \\
\hline$\overline{\text { Urban }}$ & $\leq 10$ & 19,802 & $\begin{array}{ll}792 & 198\end{array}$ & 2 & 4 & 200 & $6 / 1.98=3.0$ \\
\hline Rural & $>10$ & 160,198 & 64081602 & 16 & 24 & 150 & $40 / 16.02=2.5$ \\
\hline
\end{tabular}

way to hospital divide by 56) (Figure 1). The reasons given for not complying with the referral advice among the 19 were: "No money for the hospital" (9), "No money for transport" (2), "No money" unspecified (4), "Delivered on the way" (2), and "No reason" (2).

\section{Unmet obstetric need by UON indicator}

Ninety-seven women, including 26 referrals, were treated in the two hospitals due to complications. Sixty-eight of these women underwent major obstetric interventions (MOI) i.e. C/S or laparatomy. The majority of absolute maternal indications were cephalo-pelvic disproportion (CPD). Non-absolute maternal indications (NonAMI) included all dynamic dystocia, e.g. prolonged labour without documentation of obstruction (Table 4).

Table 5 presents the unmet need of MOI for AMI in Rufiji by distance travelled by women to the hospitals. The MOI/AMI rate per 100 expected births (EB) was 2.5\% for mothers residing more than $10 \mathrm{~km}$ from the nearest hospital and 3.0\% for women living closer to hospitals however the difference was not significantly $(p=0.65)$. These rates were all above the UON reference of $1 \%$.

\section{Caesarean rate}

The C/S rate in the whole district was 4.1\% (65/ $1,587)$ which is lower than the minimum recommended of $5 \%$.

\section{Accessibility}

The distance travelled by a patient who attended hospital was estimated from the centre of the administrative subdivision in which the patient's village was located to the respective hospitals. The median distance between the patient's village and the hospital was $20 \mathrm{~km}$ (Range 1-150) and the median time to access a comprehensive EOC institution was 45 minutes (Range 15-540). This, however, did not include the waiting time for finding means of transport.

\section{Case fatality rate (CFR)}

There was one death in hospital in 97 complicated cases, i.e. the hospital-based CFR was 1.0\%. However, there were 3 reported maternal deaths of women who had been seen at the lower level of care during the three-month period and referred to hospital level but died before arrival. Thus, the overall CFR was $2.0 \%$ (4/205). 


\section{Discussion}

More than $85 \%$ of the deliveries in the study area took place in institutions, which is an unusually high figure for a developing country and much higher than the 55\% reported from northern Tanzania ${ }^{14}$. There may be several reasons for this finding, including a community health project in this area since 1997 and that may have had positive effects on the community perceptions of the quality of maternal care in institutions ${ }^{15}$.

In any case, the high rate of institutional deliveries makes the Rufiji district suitable for studies on quality of obstetric care. It also shows that accessibility was good during the study period. A study during one year would be needed to study seasonal variations in accessibility due to the rainy seasons.

Women with delivery complications, especially those with a previous history of a $\mathrm{C} /$ $\mathrm{S}$, tended to bypass lower levels as "self-referrals" to the nearest hospital. About $40 \%$ of women with complications were referred to hospitals from peripheral units but less than half of them arrived, indicating a poor compliance with referrals.

In spite of a high proportion of institutional deliveries and good access to well-functioning hospitals, four maternal deaths occurred. This indicates that the whole healthcare system does not function well. Our study reveals that the referral system must be improved to lower maternal mortality. Other studies ${ }^{16,17}$ have shown that training traditional birth attendants (TBAs) and integrating them into the health-care system could reduce perinatal and maternal mortalities and reduce unnecessary obstetric interventions. However, given the existing situation in this study, very little could have been achieved by trained TBAs without a transport.

Assessment of quality of care should be based on the inter-relationship between structure, process and outcome components of a health intervention and no single dimension alone is sufficient to measure quality of care. ${ }^{18}$

Both hospitals in the district qualified as comprehensive EOC institutions, which is sufficient according to UN indicators. If UN indicators were strictly adopted, however, no institution below hospital level would have qualified as a basic EOC institution and only one of the hospitals as a comprehensive EOC unit. This illustrates that these indicators are less applicable in small units and limited observation periods, and was the rationale for the structuralprocess quality modification adopted in this study.

We developed a parallel data collection, since the routinely collected data, especially below hospital level, were not appropriate for the study. Furthermore, our findings indicate that routine data may not be sufficient for assessing quality of care using $\mathrm{UN}$ or $\mathrm{UON}$ indicators.

The proportion of all deliveries in EOC institutions in our study was above the minimum level of $15 \%$ recommended by the UN guidelines. It may be questioned whether this indicator is realistic ${ }^{19}$. This would require that all complications and complications only are delivered in EOC institutions, which is an unrealistic assumption.

In our study, by using this definition, the met need for obstetric care of $62 \%$ was considerably higher than reported from Mozambique, Nepal, Senegal ${ }^{20}$ and Eritrea ${ }^{21}$. Under-reporting of obstetric emergencies and over-reporting due to double counting have been observed in a system developed to monitor obstetric services in Malawi ${ }^{22}$. A comprehensive parallel data collection, as the one instituted in this study may be more reliable.

The problem of definition of obstetric complications is another reason for variations in the met need indicator. In the study area, the cutoff point for diagnosis of haemorrhage was blood loss in excess of $500 \mathrm{ml}$. The amount of bleeding was based on the perception of health workers and patient's since measurement tools

African Journal of Reproductive Health Vol. 9 No.3 December 2005 
were not used. Inconsistencies in the definition of blood loss have also been reported by Goodburn, et. al. in Malawi ${ }^{22}$. Complications of abortion included infection or persistent haemorrhage, requiring evacuation of retained products. In settings where cases of abortions are common, this could contribute to an inflation of the met need indicator since only few abortions really need any intervention ${ }^{23}$. In countries like Tanzania, where induced abortion is illegal these cases may be labelled as complications of spontaneous abortion to cover for the legal aspect. The diagnostic difficulty to separate cephalo-pelvic disproportion from other causes of prolonged labour is another notorious problem, especially when partograms are not used.

The rate of $\mathrm{C} / \mathrm{S}(4.1 \%)$ in our study is slightly lower than $4.6 \%$ reported from six districts in northern Tanzania ${ }^{14}$. Also to the recommended minimum of $5 \%$. The assumption that when the $\mathrm{C} / \mathrm{S}$ rate is low, the majority of operations are done for maternal indication may not be valid. In our case, at least $12 \%$ of the $\mathrm{C} / \mathrm{S}$ was done on foetal indications. A large variation in the proportion of sections performed for maternal indications has been reported in Senegal, where the rate of $\mathrm{C} / \mathrm{S}$ is as low as 1.2 , and from many countries a relatively low MMR has been reported with a $\mathrm{C} /$ $\mathrm{S}$ rate of less than $2.5 \%{ }^{19}$. A rise in the $\mathrm{C} / \mathrm{S}$ rate does not necessarily indicate progress in reducing maternal mortality and fixing the arbitrary minimum rate of $5 \%$ may not be adequate if only maternal mortality is addressed.

The CFR is an indicator of quality of emergency obstetric care at hospital level ${ }^{1}$. In our study, only one death occurred shortly after arrival to hospital in 97 complicated cases, which is in accordance with UN indicators of acceptable quality. Maternal death or near-death audits, may help improving case management ${ }^{20}$. The hospital CFR is of limited significance where a large proportion of complicated obstetric cases are, as in this study, delivered outside health institutions. Three maternal deaths during transport highlighted the importance of the referral system for maternal mortality and therefore should also be assessed in relation to quality of obstetric care.

\section{Unmet obstetric need}

Considering $\mathrm{UON}$ indicator and a reference ratio of $1-2 \%$ maternal mortality ratio for a population without access to any obstetric care ${ }^{9},{ }^{12}$ if major surgical interventions in a study area (usually C/ S) are below $1.0 \%$, this would be regarded as an "unmet obstetric need". Conversely, major interventions in excess of $2.0 \%$ would indicate that operative deliveries are made on other indications than to avert maternal mortality. Our finding of four maternal deaths in the study area, despite the MOI for AMI ratio of 2.5\% for mothers residing more than $10 \mathrm{~km}$ from the nearest hospital and 3.0\% for women living closer to hospitals, may indicate limitation of this indicator for quality assessment as a management tool at district level.

The method is further limited by the difficulties involved in a retrospective differential diagnosis between obstructed labour that is directly life-threatening to the mother and less severe disproportions that may cause considerable maternal morbidity.

The indicators of Met need (UN) and Unmet Obstetric Need (UON) are designed to identify whether women who need obstetric care really receive it. Both indicators are based on the diagnosis of direct obstetric complications that may need a skilled provider. For the Unmet need indicator the reference ratio, usually $1-2 \%$, is far below the 15\% used for the Met need indicator. To transform one into the other is very difficult. The UON reflects near-death maternal complications, and is thus more closely related to the reduction of maternal mortality. However, it does not include non-surgical but life-saving, medical interventions, or such a common procedure such as removal of retained placenta. Furthermore, 
110 African Journal of Reproductive Health

the reference rate estimated from an urban population with good access to hospital care makes it less valuable in a rural setting with restricted access to care and weak referral systems.

\section{Conclusion}

This study has demonstrated the inadequacy of $\mathrm{UN}$ and UON-network process indicators in monitoring the activities necessary to reduce maternal mortality in a low-resourced country setting.

Using the UN and UON process indicators, we got contradicting results of met and unmet need for obstetric services observed in Rufiji district. The process indicators did not clearly identify areas for improvement and hence other sources of information, including community based data and individual case audits, will be necessary to complete the information from these indicators. The study shows that poor performance of the referral system may cause an unacceptably high maternal mortality, in spite of good access to well functioning institutions. The study calls for more research on factors influencing compliance with referral advise as well as to establish more well-defined indicators linked to activities for reducing maternal mortality.

\section{Acknowledgement}

We are grateful to the District Medical Officer of Rufiji district and all health workers/data collectors who supported and participated in this study. We thank Kerstin Carlstedt for her expert assistance in data entry and management. This study was funded by Swedish Agency for Research and Co-operation with Developing Countries (SAREC) under collaboration between MUCHS, Tanzania, and Uppsala and Umea Universities of Sweden.

\section{REFERENCES}

1. UNICEF/WHO/UNFPA. Guidelines for Monitoring the Availability and Use of Obstetric Services. 2nd Edition ed. New York: UNICEF; 1997.

2. Rosenfield A, Maine D. Maternal mortality-a neglected tragedy. Where is the $\mathrm{M}$ in MCH? Lancet. 1985;2(8446):83-85.

3. WHO. Maternal Mortality in 2000: Estimates developed by WHO, UNICEF,UNFPA. World Health Organisation. Available at: http/ /www.who.int/reproductive -health/publications/maternal_mortality_2000/ mme.pdf. Accessed July 2005.

4. Urassa EJN, Massawe S, Lindmark G, Nystrom L. Maternal mortality in Tanzania - medical causes are interrelated with socioeconomic and cultural factors. $S$ Afr Med J. 1996;86:436-444.

5. Macleod J, Rhode R. Retrospective followup of maternal deaths and their associated risk factors in a rural district of Tanzania. Trop Med Int Health. 1998;3:130-137.

6. McDonagh M. Is antenatal care effective in reducing maternal morbidity and mortality? Health Policy Plann. 1996;11(1):1-15.

7. WHO. Essential elements of obstetric care at first referral level. London, Basigstoke: Macmillan Press Ltd; 1991.

8. Rooney C. Antenatal care and maternal health: How effective is it? Geneva: Maternal Health and Safe Motherhood Programme,WHO; 1992.

9. UON-Network. Tackling unmet need for major obstetric interventions: concepts, general principles and international network. Available at: http://www.itg.be/uonn/ pdf/Guide2-JAN99.pdf. Accessed November 2003.

10. MOH. Rufiji district health plan. Dar es Salaam, Tanzania: Ministry of Health; 1998.

11. Kielmann AA, Janovsky K, Annett H. Assessing district health needs, services and systems: protocols for rapid data collection and analysis. London and Basingstoke: Macmillan and

African Journal of Reproductive Health Vol. 9 No.3 December 2005 
AMREF; 1995.

12. Belghiti A, De Brouwere V, Kegels G, Van Lerberghe W. Monitoring unmet obstetric need at district level in Morocco. Trop Med Int Health. 1998;3(7):584-591.

13. UON-Network. Tackling unmet needs for major obstetric interventions; case studiesMali. Available at: http://www.uonn.org/ pdf/cs mali eng.pdf. Accessed accessed February, 2005.

14. Olsen Q.E, S. N, O.F. N. Complicated deliveries, critical care and quality in emergency obstetric care in Northern Tanzania. Int J Gynaecol Obstet. 2004;87:98-108.

15. Schellenberg JA, Bryce J, de-Savigny D, et. al. The effect of integrated management of childhood illiness on observed quality of care of under-fives in rural Tanzania. Health Policy Plan. 2004;19(1):1 - 10.

16. van Roosmalen J, G W, J S, Massawe S. Integrating continous support of the traditional birth attendant into obstetric care by skilled midwives and doctors: a costeeffective strategy to reduce perinatal mortality and unnecessary interventions. Trop Med Int Health. may 2005 2005;10(5):393394.

17. Jokhio AH, Winter HR, Cheng KK. An intervention involving traditional birth attendants and perinatal and maternal mortality in Pakistan. N Engl J Med. May 19 2005;352(20):2091-2099.

18. Donabedian A. The Quality of Care; How can it be assessed? Special communication. JAMA. 1988;260(12):1743-1748.

19. Ronsmans C, Campbell OM, McDermott J, Koblinsky M. Questioning the indicators of need for obstetric care. Bull World Health Organ. 2002;80(4):317-324.

20. Bailey P, Paxton A. Averting maternal death and disability, program note; Using UN process indicators to assess needs in emergency obstetric services. Int J Gynaecol Obstet. 2002;76:299-305.

21. Gottlieb P, Lindmark G. WHO indicators for evaluation of maternal health care services, applicability in least developed countries: a case study from Eritrea. Afr J Reprod Health. Aug 2002;6(2):13-22.

22. Goodburn EA, Hussein J, Lema V, Damisoni H, Graham W. Monitoring obstetric services: putting the UN guidelines into practice in Malawi. I: developing the system. Int I Gynaecol Obstet. Aug 2001;74(2):105-117; discussion 118.

23. Pathak LR, Kwast BE, Malla DS, Pradhan AS, Rajlawat R, Campbell BB. Process indicators for safe motherhood programmes: their application and implications as derived from hospital data in Nepal. Trop Med Int Health. Dec 2000;5(12):882-890. 